\title{
JOINT ISRAELI-PALESTINIAN GRAVITY SURVEY IN THE DEAD SEA RIFT VALLEY
}

\author{
by \\ M. Rybakov \\ The Geophysical Institute of Israel \\ P.O. Box 182 \\ Lod, 71100 Israel \\ R. El-Kelani \\ Earth Sciences and seismic engineering Center \\ An-Najah University \\ P.O. Box 7 \\ Nablus, The Palestinian Authority
}

U. ten Brink

U.S. Geological Survey

384 Woods Hole Rd.

Woods Hole, MA 02543 USA

\section{U.S. Geological Survey Open-file Report 00-0341}

--DISCLAIMER-

This report is preliminary and has not been reviewed for conformity with U.S. Geological Survey editorial standards or with the North American Stratigraphic Code. The use of trade, product, or industry names in this report is for descriptive or location purposes only and does not constitute endorsement of products by the U.S. Government. Opinions and conclusions expressed herein do not necessarily represent those of the USGS. 


\section{INTRODUCTION}

The first joint geophysical survey by Israel and the Palestinian Authority was carried out in February 1999 in the vicinity of Jericho. Jericho is located within the Dead Sea Rift valley about $10 \mathrm{~km}$ north of the Dead Sea shore. 102 new gravity stations were measured jointly by the authors in order to fill a gap in the existing gravity network (Figs. 1 and 2). The data were processed and incorporated into the joint Gravity Data Base for Israel and Jordan. The project was funded by US-AID project \#TA-MOU-96-C15-165 with additional funds from An-Najah University, the Geophysical Institute of Israel, and the U.S. Geological Survey.

\section{DATA ACQuisition IN THE JeRICHO AREA}

The gravity survey was performed in the Jericho area and vicinity (Fig. 2). Field measurements were carried out using a Lacoste and Romberg Model G gravimeter (\#833). 102 new gravity stations were measured in order to fill the gap in the existing gravity network. The Beit Ha'arava base gravity station was used for the survey.

Base stations were occupied at the beginning and end of each working day. During the field survey, the daily drift was usually less than $1 \mathrm{mGal}$. Bouguer anomaly accuracy, estimated on the basis of repeated measurements (about 5\%) at a given station, was $0.26 \mathrm{mGal}$. Gravity station spacing was in the order of 500 meters.

The Geographic Positioning System (GPS) was used for geodetic measurements. The gravity stations were positioned using new GPS ProMARK X-CP instruments manufactured by the Magellan Systems Corporation. These instruments were used in the stationary differential 3-D mode. Pseudorange and carrier phase satellite data, collected on the control and remote stations at one-second intervals, were processed using the MSTAR differential post-processing system. The elevation accuracy, estimated on a number of repeated measurements and known benchmarks, is 
better than 20 centimeters. This accuracy can be obtained by using a multipath-resistant antenna for the following conditions: remote control station distance should be less than $10 \mathrm{~km}$ and occupation time about ten minutes.

The raw gravity data were reduced using several standard procedures. The latitude correction was calculated according to the 1967 Geodetic Reference System Formula. The gravity data were reduced using $2.67 \mathrm{~g} / \mathrm{cm}$ density. The terrain correction was calculated using relief in the form of a digital terrain model with a 25 meter grid, adopted from the Digital Terrain Model (DTM) compiled by J.K. Hall (Hall, 1993).

\section{PRELIMINARY RESULTS}

The results of the gravity survey are presented in the Bouguer gravity map of the Jericho area (Fig. 3). The Bouguer gravity map shows that the regional trend decreases significantly eastward. This trend, caused by the Dead Sea graben filled by very thick low-density young sediments, may reach the horizontal gravity gradient of up to $10 \mathrm{mGal} / \mathrm{km}$ in an east-west direction. The regional gravity trend calculated as a third order polynomial (Fig. 4) was removed when compiling the residual gravity map (Fig. 5). These results will be incorporated into the joint Israel-Jordanian gravity data base for the Dead Sea Rift and its vicinity that was established during US-AID project \#TA-MOU-96-C15-165. In particular, they will be incorporated into an updated gravity map of the region that will replace the present 1:250,000 map (ten Brink et al., 1998). 


\section{ACKNOWLEDGMENTS}

The authors wish to thank Dr. J. Hall for permission and helping to use the DTM, and Mr. Uri Roth for field asistance. This work was partially supported by US-AID grant TA-MOU-96C15-165.

\section{REFERENCES}

Hall, J. K., 1993. The GSI Digital Terrain Model (DTM) completed. In: R. Bogoch and Y. Eshet (eds.), GSI Current Research: V. , Jerusalem, 47-50.

ten Brink, U., Rybakov, M., Al-Zoubi, A., Hassouneh, M., Batayneh, A., Frieslander, U., Goldschmidt, V., Daoud, M., and Rotstein, Y., 1998, Bouguer gravity anomaly map of the Dead Sea transform plate boundary in Israel and Jordan, scale 1:250,000, USGS open-file report, 98-516. 


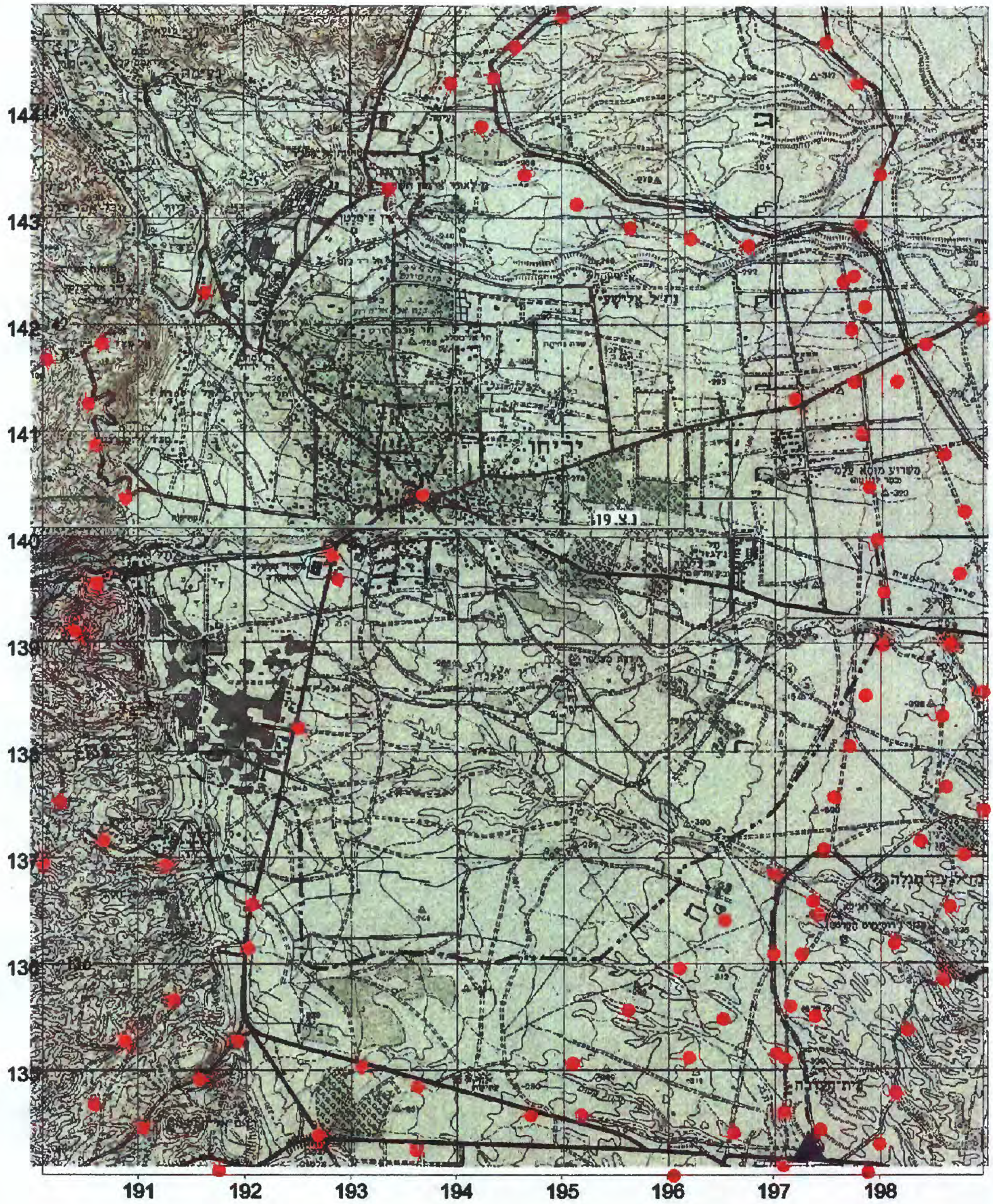

Fig. 1. Location map for gravity survey in the Jericho area.

Red dots denote the old gravity stations. Blue triangle denotes the base gravity station to be used for the survey. 


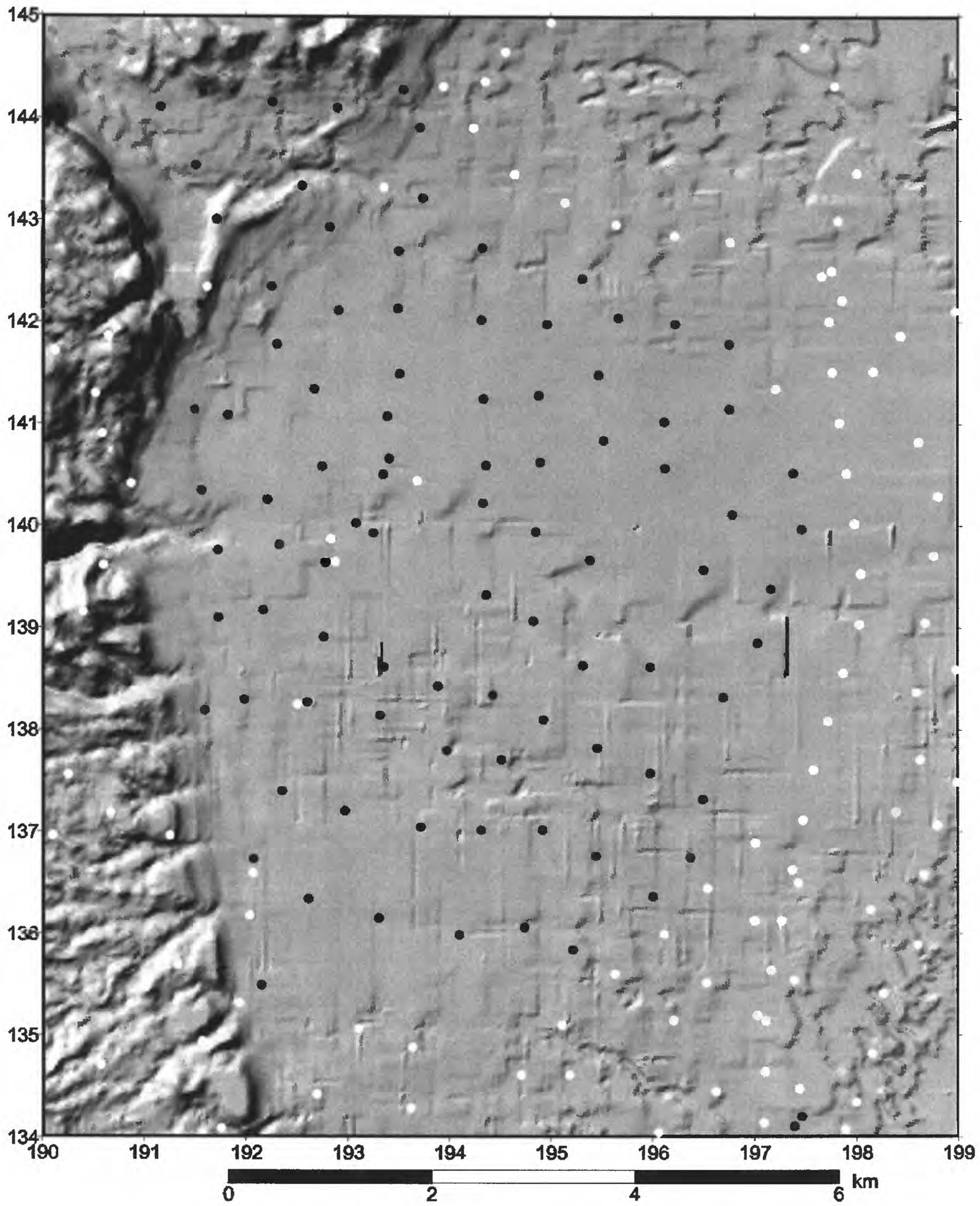

Fig. 2. Gravity coverage map of the Jericho area superimposed on the shadow relief (after Hall, 1993). Black dots donate the new gravity stations, white - old. 


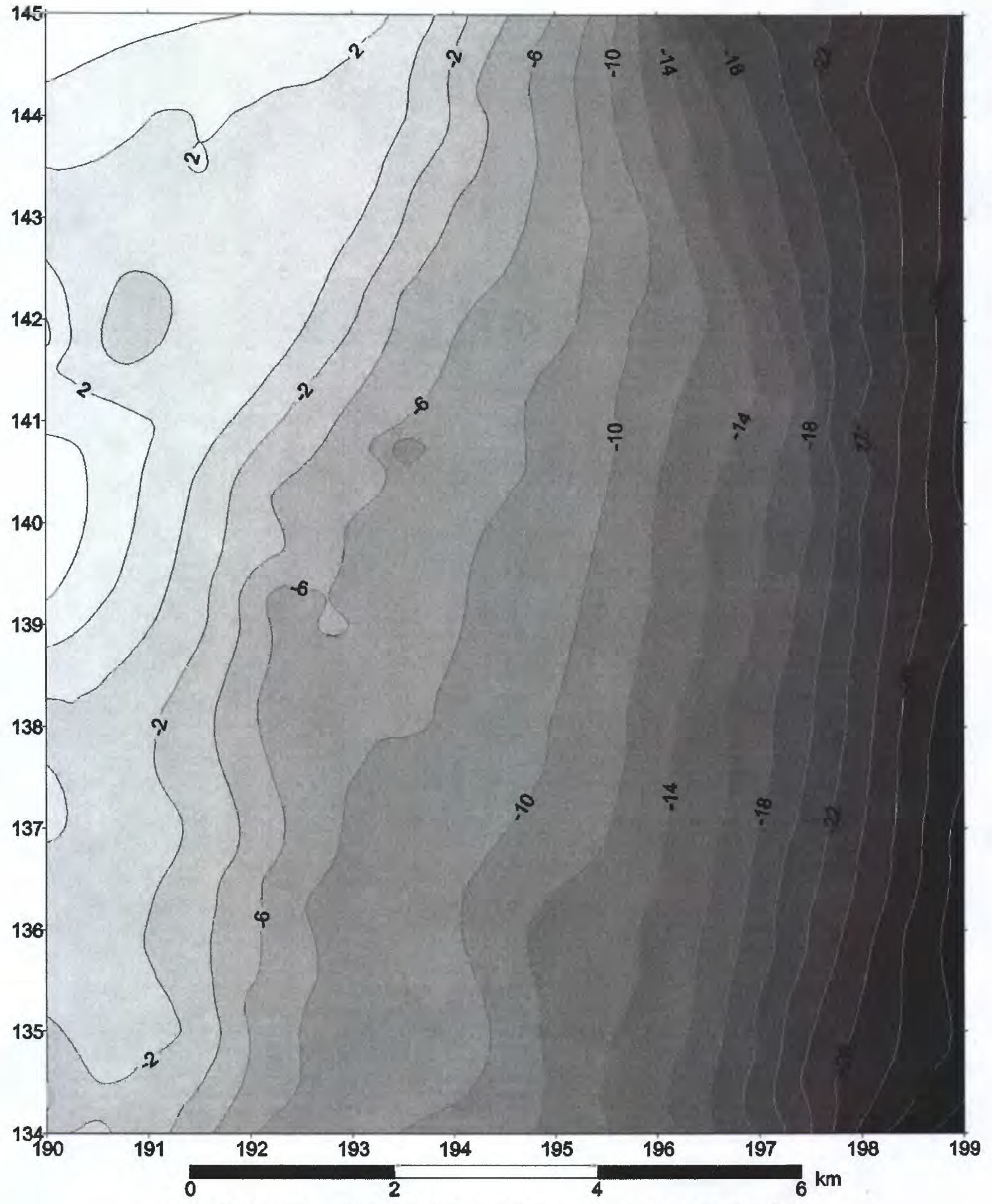

Fig. 3. Bouguer gravity map of the Jericho area. Contour interval-2 mGal. 


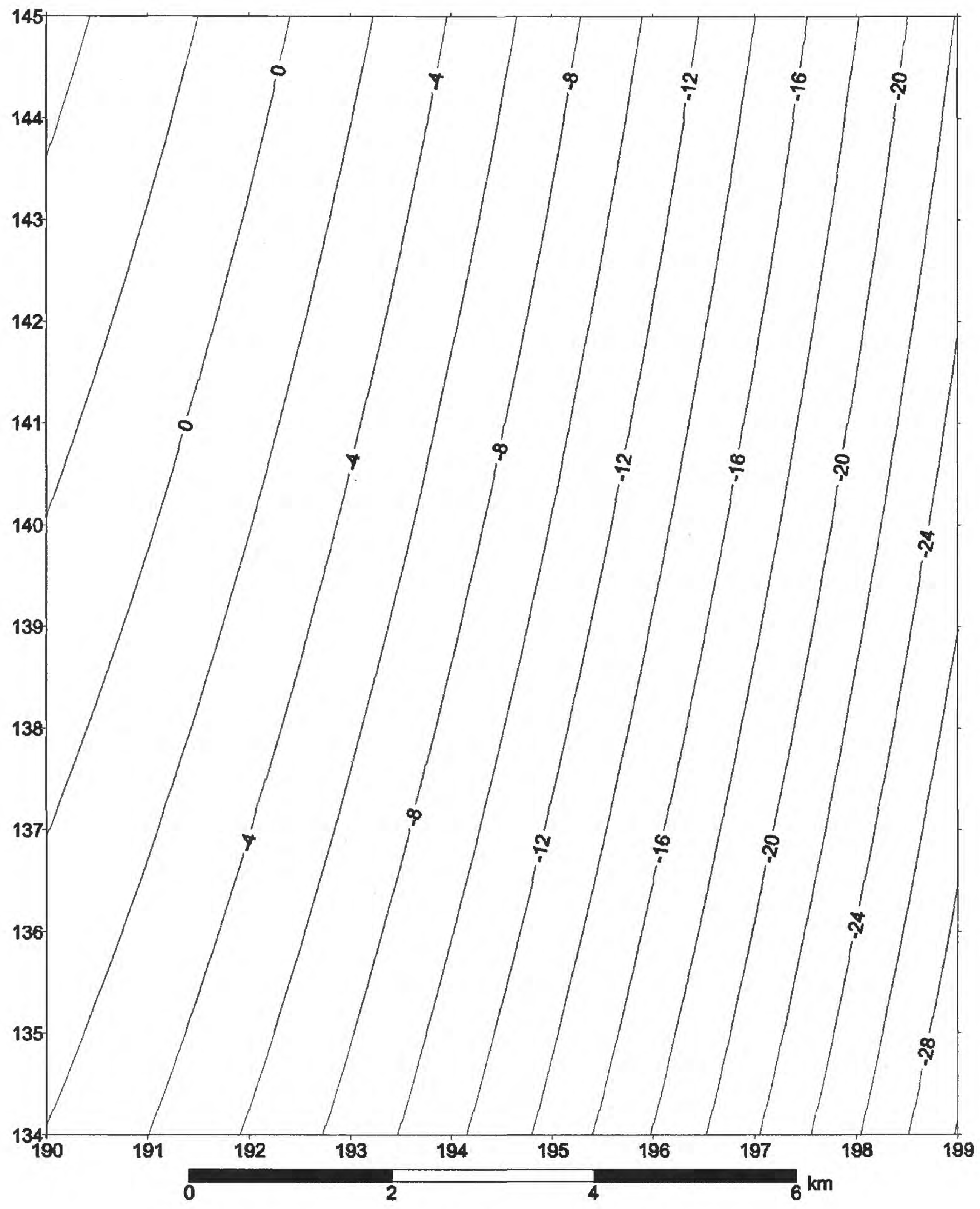

Fig. 4. Regional gravity trend of the Jericho area (3-d order polinom). 


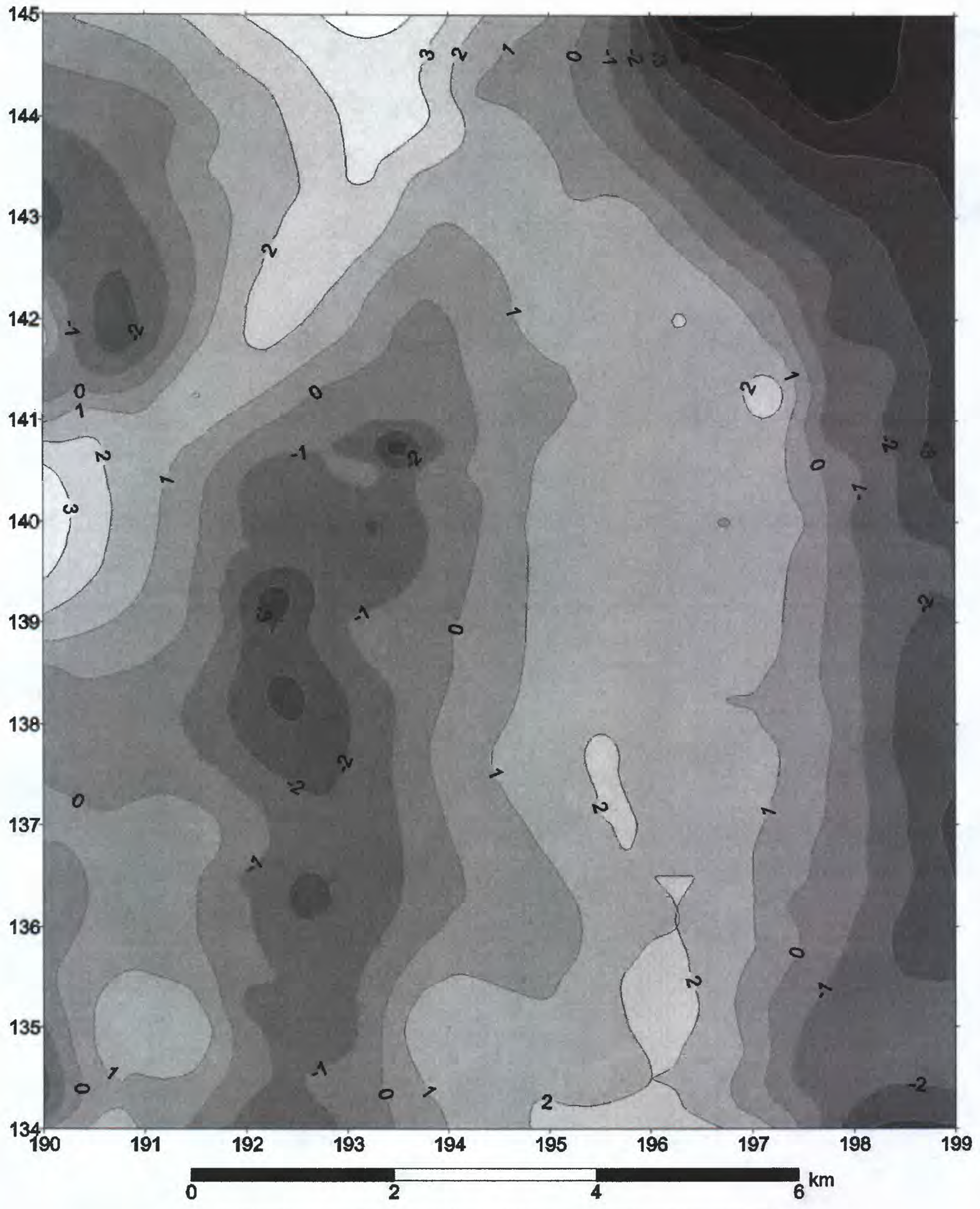

Fig. 5. Residual gravity map of the Jericho area. Contour interval-1 mGal, 